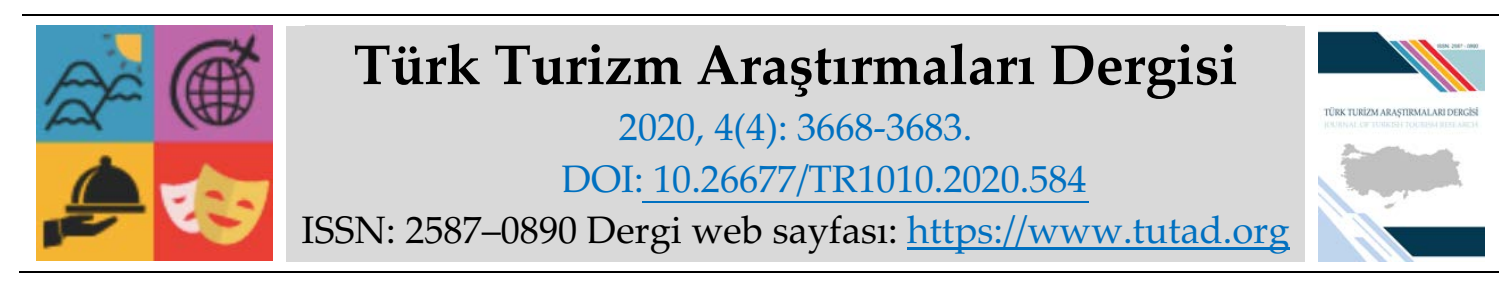

ARASTIRMA MAKALESI

\title{
COVID-19 Salgını Sonrası Yükselen Trend Kırsal Turizm: Zile Örneği
}

Dr. Öğr. Üyesi Emin ARSLAN, Tokat Gaziosmanpaşa Üniversitesi, Zile Dinçerler Turizm İşletmeciliğ̈i ve Otelcilik Yüksekokulu, Tokat, e-posta: emin.arslan@gop.edu.tr

ORCID: https://orcid.org/0000-0003-1592-8162

Dr. Öğr. Üyesi Hakan KENDİR, Tokat Gaziosmanpaşa Üniversitesi, Zile Dinçerler Turizm İşletmeciliği ve Otelcilik Yüksekokulu, Tokat, e-posta: hakan.kendir@gop.edu.tr

ORCID: https://orcid.org/0000-0002-1356-1339

Öz

Küresel anlamda turizm sektörünü derinden etkileyen COVID-19 salgını, turist tercihlerinde büyük değişiklikleri beraberinde getirmiştir. Kitle turizminin daha az tercih edildiği, bireysel turizm aktivitelerinin tercihlerde daha fazla öne çıtığı bir döneme girilmiştir. Bu çalışmada bireysel turizme en uygun türlerden biri olan kırsal turizm konu edilmiştir. Bu araştırmanın amacı alternatif turizm türlerinden biri olan kırsal turizmin COVID-19 salgını neticesinde yükselişini Tokat-Zile örneği bazında incelemektir. Araştırmada, yarı yapılandırılmış mülakat formu, odak grup yöntemiyle ve pandemi dönemi olduğu için video-konferans vasıtasıyla, Zile ilçesinde ikamet eden ve çalışan farklı mesleklerden 21 kişiye 2020 yılı Haziran-Temmuz ayları içerisinde araştırmacılar tarafından uygulanmıştır. Elde edilen veriler tablolar ve grafik hâlinde sunulmuştur. Ayrıca çalışmanın bulguları ışığında, araştırmacılar tarafından SWOT analizi yapılmıştır. Buna göre COVID-19 salgını sonrası, Zile'nin kırsalda yapılabilecek turizm aktivitelerine oldukça elverişli olduğu ancak potansiyelini değerlendirmede tanıtım başta olmak üzere, altyapı ve ulaşım konusunda eksiklikleri tespit edilmiştir.

Anahtar Kelimeler: COVID-19 Salgını, Kirsal Turizm, Zile.

Makale Gönderme Tarihi: 12.06 .2020

Makale Kabul Tarihi: 04.10 .2020

\section{Önerilen Atıf:}

Arslan, E. ve Kendir, H. (2020). COVID-19 Salgını Sonrası Yükselen Trend Kırsal Turizm: Zile Örneği, Türk Turizm Araştırmaları Dergisi, 4(4): 3668-3683.

(c) 2020 Türk Turizm Araştırmaları Dergisi. 


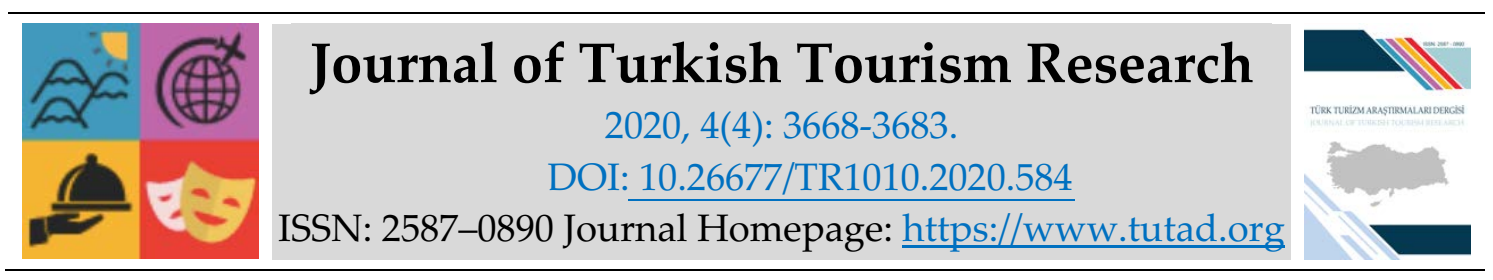

\title{
RESEARCH PAPER
}

\author{
Rising Trend Rural Tourism After the COVID-19 Pandemic: Case of Zile
}

Assistant Prof. Dr. Emin ARSLAN, Tokat Gaziosmanpaşa University, Zile Dinçerler School of Tourism and Hotel Management, Tokat, e-mail: emin.arslan@gop.edu.tr ORCID: https://orcid.org/0000-0003-1592-8162

Assistant Prof. Dr. Hakan KENDİR, Tokat Gaziosmanpaşa University, Zile Dinçerler School of Tourism and Hotel Management, Tokat, e-mail: hakan.kendir@gop.edu.tr ORCID: https://orcid.org/0000-0002-1356-1339

\begin{abstract}
The COVID-19 pandemic, which has a profound impact on the tourism industry globally, brought about major changes in tourist preferences. A transition has been made to a period when mass tourism is less preferred and individual tourism activities are more prominent in preferences. In this study, rural tourism, which is one of the most suitable species for individual tourism, has been examined the aim of this research is to examine the rise of rural tourism, which is one of the alternative tourism types, as a result of the COVID-19 pandemic, on the basis of Tokat-Zile example. In the study, the semi-structured interview form was applied to 21 people from different professions living and working in Zile district in June-July 2020, by using the focus group method and videoconference as it is a pandemic period. The data obtained are presented in tables and graphics. Also, in the light of the findings of the study, SWOT analysis was conducted by the researchers. Accordingly, after the COVID-19 pandemic, Zile was quite suitable for tourism activities in the countryside, but its deficiencies in infrastructure and transportation, especially in promotion, were identified.
\end{abstract}

Keywords: COVID-19 Pandemic, Rural Tourism, Zile.

Received: 12.06 .2020

Accepted: 04.10.2020

\section{Suggested Citation:}

Arslan, E. and Kendir, H. (2020). Rising Trend Rural Tourism After the COVID-19 Pandemic: Case of Zile, Journal of Turkish Tourism Research, 4(4): 3668-3683.

(c) 2020 Türk Turizm Araştırmaları Dergisi. 


\section{Gíriş}

Turizm talebinin çok esnek bir yapıya sahip olması, her türlü olumlu veya olumsuz durumdan hızlı bir şekilde etkilenmesi turizm hareketliliği açısından önem arz etmektedir. Dünya turizm hareketliliği içerisinde kitle turizmi olarak adlandırılan deniz-kum-güneş üçlüsüne yoğunlaşan talebin, salgın hastalıklar, ekonomik krizler ve doğal afetler sonucunda olumsuz bir şekilde etkilendiği gözlenmektedir. 2019 yılının Aralık ayında Çin'in Hubey eyaletindeki Wuhan şehrinde ortaya çıkn yeni tip koronavirüs (COVID-19) salgını, dünya düzeninin temelden değişmesine neden olmuştur. COVID-19 salgınının ortaya çıkışıyla birlikte, ekonomiye ciddi katkılar sunan tüm sektörlerde olduğu gibi turizm sektörünün de derinden etkilendiği gözlenmektedir. Salgınla birlikte, turizm sektörü açısından özellikle uluslararası seyahate katılan kişi sayısının azaldığı, rezervasyon iptalleri neticesinde konaklama işletmelerinin açılamadığı ve bu yeni düzene ayak uydurmak zorunda kalan işletmelerin de yüksek maliyetlerle karşı karşıya kaldığı bilinmektedir (Chang vd., 2020).

COVID-19 salgınının tüm dünyada hızlı bir şekilde yayılması sonucunda, turistik faaliyetlerde kitleselden bireysele bir diğer ifadeyle alternatif turizm aktivitelerine dönüşümün hızlanacağ 1 düşünülmektedir. Özellikle salgın sonrası, küçük gruplar halinde gerçekleştirilebilen, sosyal mesafenin korunabildiği, hijyen faktörlerinin daha fazla dikkate alınabildiği kırsal turizm aktivitelerinin ulusal ve uluslararası düzeyde dikkat çekeceği göze çarpmaktadır. Türkiye, coğrafyası gereği birçok alternatif turizm türüne olanak sağladığı gibi kırsal turizm anlamında da çok önemli potansiyele sahiptir (Karabatı vd., 2009; Artuğer ve Kendir, 2013). Tokat'ın Zile ilçesi de kırsal turizme elverişli potansiyel alanlardan biridir. Özellikle COVID-19 pandemisi neticesinde sosyal mesafeye uygun, kalabalık ortamlardan uzak bir yerleşim yeri olduğu için Zile, araştırmacılar tarafından incelenmeye değer görülmüştür. Bu bilgiler ışığında çalışmanın amacı, alternatif turizm türlerinden biri olan kırsal turizmin COVID-19 salgını sonrası yükselişini Tokat-Zile örneği özelinde incelemektir.

\section{KAVRAMSAL ÇERÇEVE}

\section{Kirsal Turizm}

Uluslararası turizm hareketliliğine katılan kişi sayısının sürekli artış gösterdiği bilinmektedir. UNWTO (Birleşmiş Milletler Dünya Turizm Örgütü)'ya göre, 2018 yılında dünya genelinde 1.4 milyardan fazla insanın turizm faaliyetlerine aktif olarak katıldığı belirtilmektedir. Bununla birlikte 2018 yılında uluslararası turizm gelirleri 1.7 trilyon \$ olarak hesaplanmıştır (UNWTO, 2019). UNWTO'nun 2011' de yayınladığı rapora göre, 2030 yılında uluslararası turist sayısının 1.8 milyar kişiye çıkması beklenmektedir (UNWTO, 2011). Ancak 2020 yılının başlarında Çin'de ortaya çıkan ve tüm dünyayı kasıp kavuran COVID-19 salgını, turizmle ilgili tüm planlamaları altüst etmiştir. UNWTO'nun 2020 Mayıs ayında yayınladığı rapora göre, uluslararası turizm hareketliliğine katılan kişi sayısı ilk çeyrekte \%22 azalmış ve tüm yıl boyunca bu azalmanın \%80'e kadar çıkması tahmin edilmektedir. Dolayısıyla 2020 yılında dünya turizm faaliyetlerine katılan kişi sayısının 1.1 milyar ve turizm gelirlerinin de 1.2 trilyon \$ azalacağı öngörülmektedir (UNWTO, 2020). Bu bilgiler doğrultusunda turizm sektörünün lokomotifi görevini üstlenen kitle turizminin derinden etkileneceği ve özel ilgiye dayalı, sosyal mesafenin kolay bir şekilde sağlanabileceği alternatif turizm türlerinin önem kazanacağı söylenebilir. Özellikle COVID-19 salgını sonrası; küçük gruplar halinde yapılabilen, sosyal mesafenin ve hijyenin sağlanabildiği alternatif turizm türlerinden biri olan kırsal turizmin önem kazanacağı düşünülmektedir.

Alternatif turizm türleri arasında yer alan kırsal turizmin, uluslararası (Lane, 1994; Bramwell, 1994; Fleischer ve Pizam, 1997; Kastenholz vd., 1999; Canoves vd., 2004; Kastenholz vd., 2012; 
Kastenholz vd., 2018; Cucari vd., 2019) ve ulusal (Soykan, 2003; Çeken vd., 2007; Çeken vd., 2012; Özdemir Yılmaz ve Kafa Gürol, 2012; Aydın, 2012; Deveci vd., 2013; Artuğer vd., 2013) literatürde sıkça incelendiği görülmektedir. Uluslararası literatürde kırsal alanlardaki turizm faaliyetleri çok farklı terimler altında irdelenmektedir. Bunlar; kırsal turizm (rural tourism), tarım turizmi (agritourism/agrotourism), çiftlik turizmi (farm tourism), yumuşak turizm (soft tourism), alternatif turizm (alternative tourism), vahşi doğa ve orman turizmi (wilderness and forest tourism), yeşil turizm (green tourism) ve ekoturizm (ecotourism)'dir (Roberts ve Hall, 2001: 15). Kırsal turizm kavramı, geleneksel mimari yöntemlerle inşa edilmiş bir köy evinde konaklamak, doğal ürünlerden oluşan yiyecek ve içecek hizmetinden yararlanmak ve aile tarzı misafirperverliğin hazzını yaşamak şeklinde tanımlanmaktadır (Voase, 1995; Canoves vd., 2004: 756). Tanımdan da anlaşılacağı üzere, kırsal turizm işletmeleri çok katlı ve odalı betonarme yapılardan ziyade mikro işletmeler şeklinde bir altyapıya sahiptir. Ancak, bu tarz mikro yapıdaki işletmeler, rekabet güçlerini arttırabilmek için pazarlamayı etkin bir şekilde kullanmak zorundadırlar (Campon-Cerro vd., 2017).

Kırsal turizm, kırsal alanlarda yaşayan insanların gelirinin artmasına destek olmakta ve tarımsal faaliyetlerin bir tamamlayıcısı olarak kabul edilmektedir. Bununla beraber turizm sayesinde yeni istihdam fırsatlarının ortaya çıkması ve kırsalda yaşamını sürdüren yerel halkın refah seviyesinin yükselmesi, kırsal alanlardan kentsel alanlara doğru meydana gelen göçün azalmasına yardımcı olmaktadır (Khartishvili vd., 2019).

Kırsal alanlar için önemli bir kalkınma aracı olma potansiyeli barındıran kırsal turizm, turizm pazarında oluşan yeni trendlerle de uyum göstermektedir. Kentsel alanlara özgü stres faktörlerinin (kirlilik, trafik, gürültü vb.) az olması, açık alan rekreatif faaliyetlerine olan ilginin artması, doğa ve kültürle daha fazla etkileşim kırsal turizmin bu pazar içindeki payının artmasını sağlamaktadır (Kastenholz vd., 2012). Kitle turizmine göre çevre ve kültür ile uyum sağlayan kırsal turizm, olumsuz etkileri en az olan turizm türlerinden biri olarak görülmektedir. Kırsal alanlarda yer alan küçük ve yerel işletmelerde konaklama ve yiyecek - içecek ihtiyacının giderilebilmesi, tarımsal arazinin yok olması ve betonlaşma gibi çevre sorunlarını önlemektedir. Öte yandan kırsal turizm yılın 12 ayı yapılabilmesinden dolayı da mevsimsel yoğunlaşmayı ve bölgesel taşıma kapasitesinin aşılmasını engellemektedir (Soykan, 2003). Kırsal turizm, çok sayıda farklı rekreatif faaliyeti bünyesinde barındırmaktadır. Yalnızca tarıma dayalı bir turizm türü olmayan kırsal turizm; doğa yürüyüşleri, tırmanma, kampçlık, karavancılık, binicilik, balık avlama ve kuş gözlemciliği gibi aktiviteleri de içermektedir (Lane, 1994: 9). Ayrıca kırsal turizme katılan turistlerin; eğitim ve gelir seviyelerinin yüksek, çevreye duyarlı ve tatil harcamalarının kitle turizmi harcamalarına göre daha fazla olduğu göze çarpmaktadır (Page ve Getz, 1997: 13).

Genel turizm pazarının bir parçası olarak kabul edilen kırsal turizmin önemi, turistik destinasyonların rekreasyon/turizm kaynaklarına, altyapılarına, imajına, pazara erişime ve diğer turizm ürünlerinin varllğına bağlıdır. Örneğin, kırsal turizm olanaklarına sahip Avusturya, kültür turizmi olanaklarına sahip Mısır ve deniz turizmi olanaklarına sahip Akdeniz ülkeleri gibi önemli destinasyonlar ana turistik ürün ile destinasyonun imajını bütünleştirmiştir. Öte yandan destinasyonlar sahip oldukları ana ürünlerin yaşam döngüsünü uzatabilmek adına ürün çeşitlendirme yapmak zorundadırlar (Kastenholz vd., 1999). Özellikle salgın hastalıklar, ekonomik krizler, doğal afetler gibi yaşamın her alanını etkileyen krizler sonucunda turizmin dinamiklerinde de birtakım değişimler kaçınılmaz olmaktadır. Küresel COVID-19 salgınından sonra, turizme katılanların kitle turizminden ziyade alternatif turizm türlerine yönelmeleri bu duruma örnek olarak gösterilebilir. 


\section{Salgın Hastalıklar ve Turizm}

Turizm, yapısı itibariyle her türlü krizden ve olumsuz durumdan rahatlıkla etkilenebilen, çok kırılgan bir sektördür. Küresel veya yerel açıdan farklı zamanlarda ve farklı sebeplerle turizm sektörünü negatif biçimde etkileyen krizler ortaya çıkmaktadır. Terör eylemleri, finansal ve mali krizler, salgın hastalıklar, doğal afetler, savaşlar, politik istikrarsızlıklar vb. gerekçelerle ortaya çıkan negatif durumlar turizm endüstrisini sekteye uğratmaktadır. Bu gibi olumsuz durumlar yaşayan destinasyonlarda, turizm sektörünün zarar görmesi, turist sayısının ve gelirinin ciddi oranlarda düşmesi muhtemeldir (Richardson vd., 2012:152). Turistik bir destinasyonda ya da onun çevresinde gerçekleşen olumsuz gelişmeler ve krizler, genellikle çok daha az turist sayısı ve turizm geliri ile sonuçlanmaktadır. Bu olumsuz durumlar içerisinde özellikle insan sağlığını ve güvenliğini tehdit eden virüs veya bakteri kökenli salgın hastalıklar, çok az bir risk oluştursa dahi, o destinasyonun turistler tarafından tercih edilmemesi için yeterli bir sebep olarak gösterilebilir (Lee ve Chen, 2011).

Dünya üzerinde insanlık tarihi boyunca veba, çiçek, kolera, HIV, ebola, H1N1, H5N1, SARS, MERS gibi pek çok bulaşıcı hastalık belirmiş ve özellikle son dönemlerde ortaya çıkanlar yoğun turizm hareketleri ve seyahatler ile geniş kitlelere yayılmak suretiyle, dünya geneline taşınmıştır (Hollingsworth vd., 2007; Baker, 2015). Örneğin 2002 yılında Çin'de ortaya çıkan SARS (Şiddetli Akut Solunum Yolu Sendromu) salgını, özellikle Asya'da turizm sektörü üzerinde çok ciddi bir olumsuz etki yaratmıştır. SARS salgınından en ciddi şekilde etkilenen Asya ülkeleri, Çin, Hong Kong, Tayland, Macau, Singapur ve Vietnam'da turizm sektörü adeta çökme noktasına gelmiştir (McAleer vd., 2010). SARS salgınında dünya çapında ilk 9 ayda sadece 8096 vaka ve 774 ölüm görülmesine rağmen panik havası turistleri etkilemiştir. Uluslararası turizm hareketlerini sekteye uğratan salgın, Uzakdoğu'daki ülkelerin turist sayılarında \%20'leri aşan düşüşlere sebep olmuştur (Ünlüönen ve Çeti, 2019:117). Bununla beraber SARS salgınının istihdam üzerinde de negatif etkileri söz konusudur. Öyle ki; Çin'de 2.8 milyon, Vietnam'da 62 bin, Hong Kong'da 27 bin ve Singapur'da 17 bin insanın işsiz kaldığı tahmin edilmektedir. SARS salgını nedeniyle, bu ülkelerde en fazla iş gücü kaybı yaşayan sektörler ise konaklama, ulaşım, yiyecek-içecek ve eğlence hizmetleri olmuştur (Pine ve McKercher, 2004). Farklı dönemlerde ortaya çıkan kuş gribi, domuz gribi, ebola gibi salginlar da boyutları aynı olmasa da yine SARS'la benzer etkiler yaratmıştır (Bahar ve Çelik İlal, 2020). Ancak bugüne kadar meydana gelmiş hiçbir salgın, küresel anlamda COVID-19 (yeni tip koronavirüs) salgını kadar turizm sektörünü etkilememiştir. Dolayısıyla, COVID-19 salgınının bugüne kadar, Dünya üzerinde turizm sektörü açısından görülen en etkili sağlık kökenli kriz olduğu söylenebilir.

\section{COVID-19 ve Turizme Etkileri}

Yeni tip koronavirüs veya yaygın bilinen adıyla COVID-19 bulaşıcı hastalığı, 2019 yılı Aralık ayında Çin'in Hubey eyaletindeki Wuhan şehrinde zatürre (pnömoni) şeklinde yerel bir salgın olarak ortaya çıkmıştır. İlerleyen süreçte bu virüsten kaynaklanan hastalığın, dünya çapında hızlı ve oldukça geniş boyutta bir yayılım göstermesiyle WHO (Dünya Sağlık Örgütü) tarafından, Şubat 2020'de önce epidemi daha sonra ise pandemi (dünya çapında salgın) ilan edilmiştir (Lu vd., 2020: 401; WHO, 2020). 2020 Mart ayından itibaren çok hızlı bir biçimde tüm ülkelerde yayılmaya başlayan COVID-19 virüsü, insan ve toplum sağlığı açısından ciddi tehdit oluşturması ve ölümcül sonuçlara sebebiyet vermesi nedeniyle kısa sürede tüm dünyada yaşam şekillerinin gözden geçirilmesine yol açmıştır (Higgins-Desbiolles, 2020; Li vd., 2020; Wang vd., 2020). Küresel bir boyutta tüm insanlığı etkisi altına alan salgın neticesinde, 20 Temmuz 2020 itibariyle 14.7 milyonu aşan toplam vaka ve 610 binin üzerinde ölüm gerçekleşmiştir (Worldometer, 2020). 
Dünya genelinde hemen hemen tüm iş kollarında olduğu gibi turizm sektöründe de COVID-19 salgınının çok ciddi etkileri ortaya çıkmıştır. Dünya turizm hareketleri açısından bugüne kadar alışılagelmiş tüm algıları yıkan bu salgın adeta bir dönüm noktası olarak görülebilir. COVID-19 virüsü yayılmaya başladığında ülke yönetimlerinin birbiri ardına sınırlarını kapatması, uluslararası turizmin durma noktasına gelmesine sebep olmuştur (Gössling vd., 2020). Ülkeler, sınırları içerisinde ise seyahat, konaklama ve eğlence sektörlerine yönelik yasaklar veya kısıtlamalar getirerek, sosyal faaliyetleri en aza indirmiştir ve insanlara evlerinden zorunlu olmadıkça çıkmamalarını söylemiştir. Hükümetler tarafından insan sağlığını korumak için alınan bu önlemler, iç turizminde durmasına sebebiyet vermiştir. Dünyanın dört bir yanındaki hükümetler, sağlık sistemlerinin çöküşünü ve toplu ölümleri engellemek adına çok haklı olarak bu tedbirleri almışlardır. Öte yandan ülke yönetimleri, halk sağlığını korumaya çalışırken, ekonomilerini sürdürmek ve tehlikeli bir biçimde artan işsizlik ve yoksulluk seviyelerini önlemek arasında bir denge kurmaya çalışmaktadır. Ancak, COVID-19 virüsünün hiç beklenmedik bir zamanda ortaya çıkması ve hızla yayılması, ulaşımdan konaklamaya kadar turizm sektöründe faaliyet gösteren tüm işletmelerin hazırlıksız bir biçimde yakalanmasına neden olmuştur. Salgından önce turizm sektörü, overtourism (aşırı turizm) olgusunu tartışırken ve hatta bu soruna çözüm ararken, salgından sonra sektör ekonomik açıdan neredeyse çökme noktasına gelmiştir (Acar, 2020; Bahar ve Çelik İlal, 2020).

Ortaya çıtığ 1 andan itibaren ilk başta Çin Halk Cumhuriyeti ve Güney Kore olmak üzere ilerleyen günlerde Avrupa Kıtası'nı, sonrasında da tüm dünyayı saran COVID-19 salgını, turizmdeki etkisini ilk olarak seyahat ve konaklama kontratlarının iptal edilmesi şeklinde göstermiştir. Çok geçmeden sektörde faaliyet gösteren tüm iş kollarında iptallerin ve kapanışların artarak devam etmesi, turizm işletmelerinin çok zor günler yaşamasına sebebiyet vermiştir (Hoque vd., 2020). Yapılan bir çalışmada COVID-19 salgınının turizm sektörü üzerindeki ekonomik anlamda olumsuz etkilerinin en iyi ihtimalle 6-12 ay süreceği tahmin edilmektedir (Gössling vd., 2020:15). Salgının dünya çapında yarattığı panik havasının turizm sektörü üzerinde olumsuz etkilerinin olduğu görülmektedir ve bu durumun turizm faaliyetlerinde köklü değişikliklere neden olacağı artık bilinmektedir (Higgins-Desbiolles, 2020; Bahar ve Çelik İlal, 2020; Abu Bakar ve Rosbi, 2020).

Bu noktaya kadar yapılan açıklamalar ışığında kırsalda yapılacak turizm aktivitelerinin COVID19 salgını neticesinde ortaya çıkan sosyal mesafe kuralları ve bireysel hareket etme tavsiyeleri nedeniyle daha çok tercih edileceği öngörülebilir. Dolayısıyla kırsal turizmin dünya genelinde yükseliş trendine gireceği söylenilebilir. Türkiye de coğrafi yapısı gereği kırsal turizme oldukça elverişli imkânlar sunmaktadır. İnsanların değişen turizm tercihlerinin kırsal turizme yönelmesi sonucunda, Türkiye'nin bu pastadan pay alma olasılığı yüksektir. Bu araştırmanın gerçekleştirildiği yer olan Tokat'ın Zile ilçesi de Türkiye' de kırsal turizm potansiyeli yüksek olan bir konumda yer almaktadır.

\section{Zile ile İlgili Genel Bilgiler}

Tokat'ın en büyük ilçelerin biri olan ve il merkezinin yaklaşık $65 \mathrm{~km}$. batısında yer alan Zile'nin; doğusunda Turhal ilçesi, güneyinde Artova ve Yozgat'a bağlı Kadışehri ilçesi, batısında Yozgat'a

bağlı Çekerek ilçesi ve Amasya'nın Göynücek ilçesi, kuzeyinde ise Amasya bulunmaktadır (Harita 1). Zile'nin yüzölçümü $1512 \mathrm{~km}^{2}$ ve rakımı 710 metredir (Trak ve Zengin, 1994: 25; Dönmez vd., 2017). 


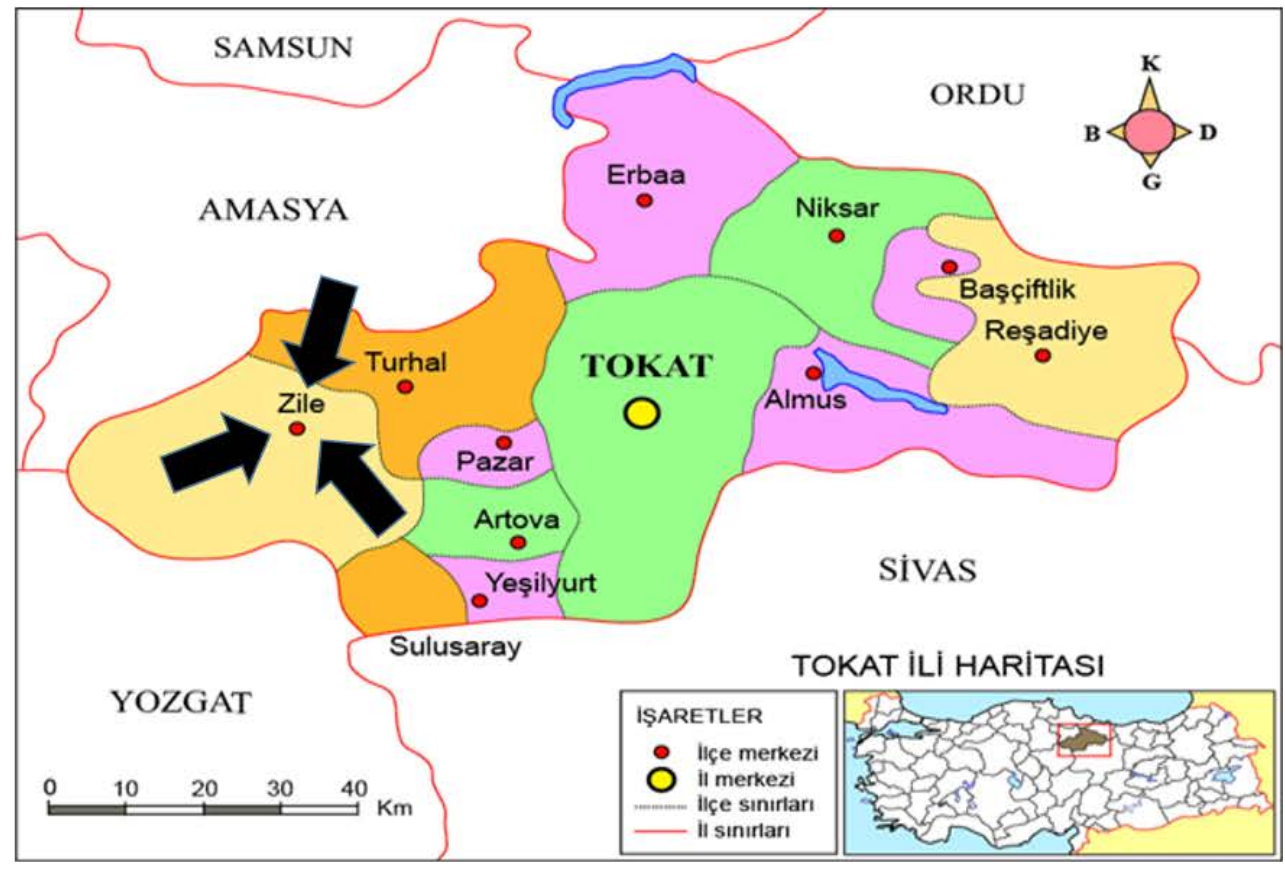

Harita 1: Zile'nin Konumu (Coğrafya Harita, 2020)

Anadolu'nun en eski yerleşim yerlerinden biri olan Zile, güneyden doğu batı ekseninde uzanan ve en yüksek tepesi 1892 metreyi bulan Deveci Dağları ile kuzeyden yine doğu batı ekseninde uzanan yüksek tepelerle çevrilmiştir. Orta Karadeniz Bölgesi'nin güneyinde yer alan ve İç Anadolu Bölgesi'nin kuzeyine komşu olan Zile, her iki bölgenin de iklim özelliklerini taşımaktadır (Zile Belediyesi, 2020). Zile'de yaşayan yerel halk genel olarak tarım ve hayvancılık ile uğraşmaktadır. İlçe ekonomisine önemli katkı sunan tarım ürünlerinin başlıcaları; buğday, arpa, nohut, şeker pancarı, ayçiçeği, üzüm, kiraz, ceviz, domates, mercimek, fiğ, fasulye, patates ve soğandır (Trak ve Zengin, 1994: 44).

Adrese dayalı nüfus kayıt sistemine göre ilçenin 2007 yılında toplam nüfusu 68.937 kişi iken, 2019 yılı toplam nüfusu 54.297' dir. İlçeye bağlı 114 köy ve 20 mahalle bulunmaktadır (TÜİK, 2020). Sanayi üretiminden ziyade tarımsal üretimin yapıldığı ilçede, istihdam olanaklarının sinırlılığından dolayı büyük şehirlere göçün yaşandığı ve yıllar itibariyle nüfusun azaldığı görülmektedir. Dolayısıyla Zile'de insan hareketliliğinin seyrekleşmesi, ilçenin doğaya dönük, kırsal aktivitelere uygun ve daha sakin bir yapıya bürünmesine yol açmıştır. Zile'nin kırsal alanlarının tahrip edilmemiş olması, özellikle COVID-19 salgını sonrasında kırsal turizm faaliyetleri açısından ön plana çıkmasını sağlama potansiyeline sahiptir.

\section{YÖNTEM}

Çin'in Wuhan kentinde başlayıp Dünya geneline yayılan COVID-19 salgınından sonra, insanlar kitle turizmi hareketlerinden uzaklaşarak daha bireysel ve sosyal mesafeyi koruyucu turizm türlerine ilgi duymaya başlamıştır. Dolayısıyla bu araştırmanın amacı alternatif turizm türlerinden biri olan kırsal turizmin COVID-19 salgını neticesinde yükselişini Tokat-Zile örneği bazında incelemektir. Bu amaç doğrultusunda araştırmanın hedef kitlesi olarak Tokat-Zile ilçesinde çalışan ve ikamet eden bireyler seçilmiştir.

Araştırmada nitel araştırma tekniklerinden olgubilim (fenomenoloji) türü tercih edilmiştir. Bunun sebebi olarak olgubilim kavramının, farkında olunan ancak derinlemesine ve ayrıntılı bir bilgiye sahip olunmayan olgulara odaklanması gösterilebilir. Söz konusu olgular, karşılaşılan 
olaylar, deneyimler, algılar, yönelimler, kavramlar ve durumlar gibi çeşitli biçimlerde ortaya çıkabilmektedir. Dolayısıyla tümüyle yabancı olmayan aynı zamanda da tam olarak kestirilemeyen durumları incelemeyi amaçlayan çalışmalar için olgubilim, uygun bir araştırma zemini oluşturmaktadır (Yıldırım ve Şimşek, 2005).

Olgubilim tekniğinden yola çıkarak araştırmada, yarı yapılandırılmış görüşme tekniği uygulanmış ve katılımcıların görüşleri değerlendirilmiştir. Bu görüşleri belirleyebilmek ve mevcut sorunların tespiti ile çözüm önerilerini ortaya koyabilmek amacıyla, alanda daha önce yapılmış çalışmalar incelenerek, araştırmacılar tarafından altı sorudan oluşan bir form geliştirilmiştir. Görüşme yöntemi, araştırma amacına uygun olarak hazırlanan soruların veya ifadelerin, görüşüne ihtiyaç duyulan hedef kitleye araştırmacı tarafından sorularak cevap alınması sürecidir (Ural ve Kılıç, 2013). Yarı yapılandırılmış görüşme tekniğinin kullanılmasının sebebi ise araştırma kapsamında elde edilmek istenen verilere, daha önce farklı araştırmalarda kullanılmış ölçekli sorularla ulaşmanın mümkün olmamasıdır. Önceden hazırlanmış görüşme taslağına bağlı olarak sürdürülen yarı yapılandırılmış mülakat tekniği, araştırmacıya daha sistematik ve karşılaştırılabilir bilgi elde edebilme olanağı sağlamaktadır. Ayrıca bu teknik, görüşmenin gidişatına göre ek soru sorma veya mevcut sorularda değişiklik yapma imkânı da verebilmektedir (Yıldırım ve Şimşek, 2005). Bu bilgiler 1şığında araştırma evreninin kapsam olarak sınırlılık arz etmesi sebebiyle, yarı yapılandırılmış mülakat formu, odak grup yöntemiyle ve pandemi dönemi olduğu için video-konferans vasıtasıyla, Zile ilçesinde ikamet eden ve çalışan farklı mesleklerden 21 kişiye 2020 yılı Haziran-Temmuz döneminde araştırmacılar tarafından bizzat uygulanmıştır. Elde edilen verilerin analizinde ise, daha objektif bir değerlendirme şansı sunması sebebiyle, içerik analizi tekniği kullanılmıştır. Araştırmayı gerçekleştirebilmek için Tokat Gaziosmanpaşa Üniversitesi, Sosyal ve Beşeri Bilimler Araştırmaları Etik Kurulu'ndan 25/06/2020-E.29031 tarih ve sayılı “Etik Kurul Raporu” alınmıştır.

\section{BULGULAR}

Çalışmanın amacı ve yöntemi kapsamında gerçekleştirilen odak grup görüşmeleri neticesinde elde edilen araştırma verileri bu bölümde sunulmuştur. Öncelikle odak grup görüşmelerine katılan bireylerin kişisel ve iş hayatına dair bilgilerine yer verilmiştir. Hemen ardından, odak grup görüşmeleri neticesinde katılımclların görüşlerinden hareketle oluşturulan grafik sunulmaktadır. Son olarak katılımcların görüşlerinin daha net anlaşılması ve öne çıkan hususların daha görünür hale gelmesi için araştırmacılar tarafından hazırlanan bir matris yer almaktadır.

Tablo 1: Odak Grup Katılımcılarının Cinsiyetleri ve Çalıştıkları Sektör $(\mathrm{N}=21)$

\begin{tabular}{|l|c|c|}
\hline Cinsiyet & $\mathbf{n}$ & $\mathbf{\%}$ \\
\hline Erkek & 14 & 66,7 \\
\hline Kadın & 7 & 33,3 \\
\hline Sektör & $\mathbf{n}$ & $\mathbf{\%}$ \\
\hline Kamu & 10 & 47,6 \\
\hline Özel & 11 & 52,4 \\
\hline
\end{tabular}

Tablo 1'de odak grup görüşmelerine katılan 21 adet katılımcının cinsiyetlerine ve çalıştıkları sektöre göre dağılımı görülmektedir. Buna göre katılımcıların büyük çoğunluğunu erkekler 
oluşturmaktadır. Kadınların ise erkek katılımcıların yarısı kadar bir sayıda kaldığı görülmektedir. Yine Tablo 1'e göre katılımcıların kamu ve özel sektördeki dağılımı neredeyse birbirine eşit düzeydedir. Ancak küçük bir farkla özel sektör çalışanlarının öne çıktığı göze çarpmaktadır.

Tablo 2: Odak Grup Katılımcılarının Meslekleri/Görevleri (N = 21)

\begin{tabular}{|l|c|l|c|}
\hline Meslek/Görev & $\mathbf{n}$ & Meslek/Görev & $\mathbf{n}$ \\
\hline Belediye Başkanı & 1 & Doktor & 1 \\
\hline İnşaat Mühendisi & 1 & Öğretim Görevlisi & 1 \\
\hline Şehir Plancısı & 1 & Öğretmen & 1 \\
\hline Belediye Başkan Yardımcısı & 1 & Polis & 1 \\
\hline Otel Sahibi & 1 & Tüccar & 1 \\
\hline Restoran Sahibi & 1 & Spor Eğitmeni & 1 \\
\hline Mimar & 2 & Diş Hekimi & 1 \\
\hline Avukat & 1 & Memur & 1 \\
\hline Esnaf & 1 & Psikolog & 1 \\
\hline Mali Müşavir & 1 & Eczacı & 1 \\
\hline
\end{tabular}

Tablo 2'de odak grup görüşmelerine katılanların meslekleri/görevleri belirtilmektedir. Araştırmacılar tarafından seçilen örneklem, yerel karar vericileri ve yerelde faaliyet gösteren diğer aktörleri içermesi bakımından önemlidir. Katılımın, mümkün olduğu kadar her meslek grubunu içeren bir yelpazede sağlanması amaçlanmıştır. Tablo 2'de de görüldüğü gibi örneklemin dağılımı hedeflendiği şekilde gerçekleşmiştir.

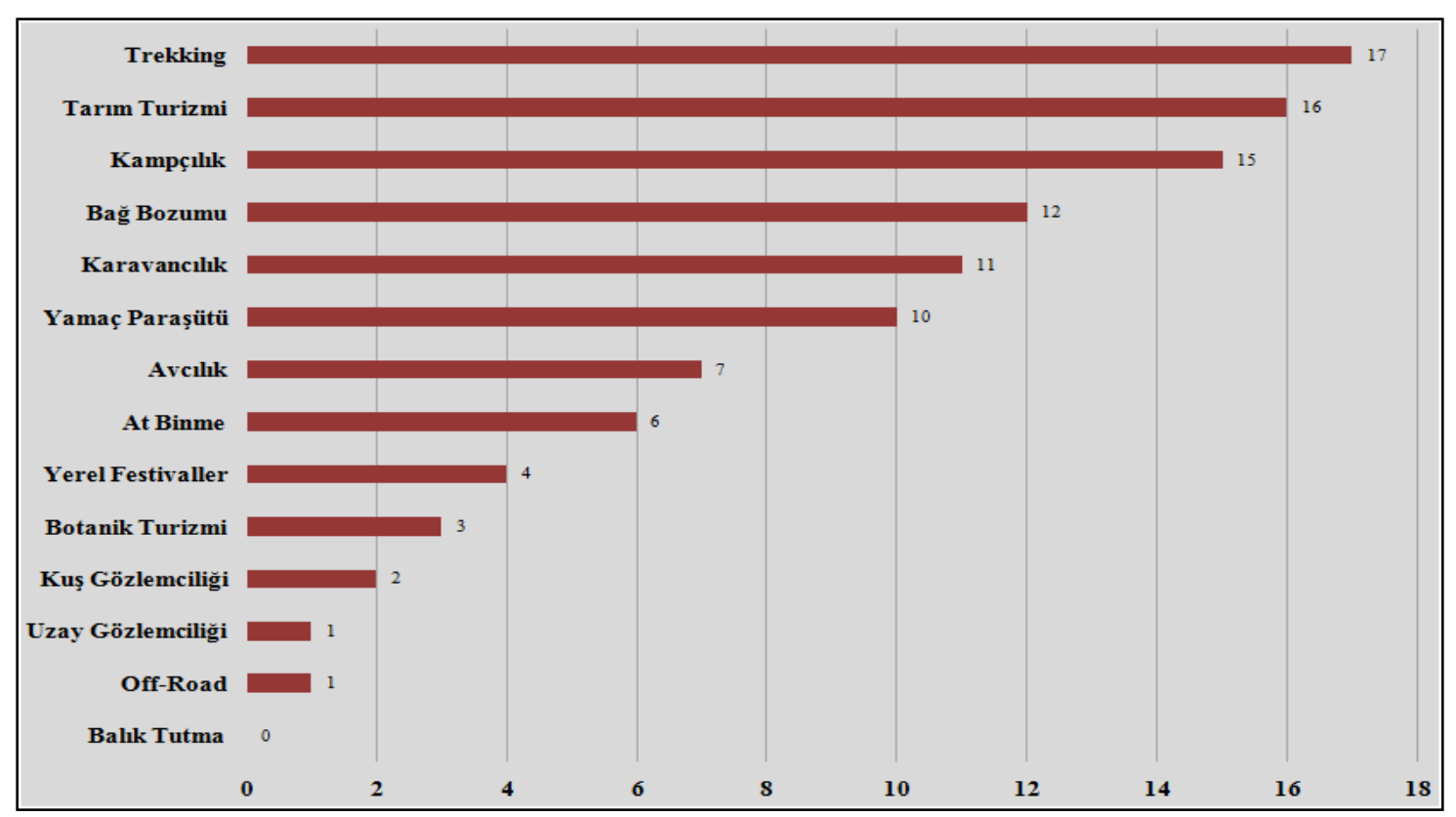

Grafik 1: Odak Grup Katılımcılarının Görüşleri Doğrultusunda Zile'de Öne Çıkan Kırsal Turizm Aktiviteleri 
Grafik 1'de odak grup görüşmeleri neticesinde katılımcılardan elde edilen veriler doğrultusunda, Tokat'ın Zile ilçesinde uygulanabilecek en fazla öne çıkan kırsal turizm aktiviteleri görülmektedir. Katılımcıların değerlendirmelerine göre Zile'ye en uygun görülen kırsal turizm aktivitesi "trekking" yani "doğa yürüyüşü" olmuştur. Zile doğası gereği trekkinge uygun ortamlar barındırdığından ve trekkingin COVID-19 neticesinde bireysel yapılmaya elverişli aktivitelerden biri olmasından dolayı sonucun bu şekilde çıkması oldukça anlamlıdır. Bununla beraber tarım turizmi, kampçılık, bağ bozumu ve karavancıllk gibi türlerin de odak grup görüşmeleri neticesinde Zile'ye en fazla uygunluğu ifade edilen aktiviteler olduğu göze çarpmaktadır. Tarım turizmi ve bağ bozumu aktivitelerinin bir tarım ve bağcılık kenti olan Zile'de öne çıması beklenen bir sonuçtur. Öte yandan kampçlık ve karavancllık aktivitelerinin COVID-19 salgınından dolayı, Türkiye genelinde popüler hale gelmesine (Anadolu Ajansı, 2020) paralel olarak Zile'de de öne çıkması anlamlı bir sonuçtur.

Tablo 3: Odak Grup Katılımcılarının Zile' de Kırsal Turizme Dair Görüşlerinin Matrisi

\begin{tabular}{|c|c|c|c|c|c|c|c|c|c|c|c|c|c|c|c|c|}
\hline 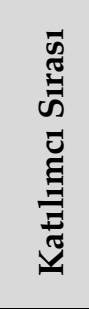 & $\underset{0}{\stackrel{\Xi}{0}}$ & 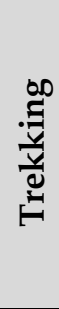 & 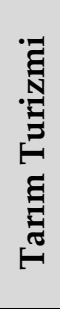 & 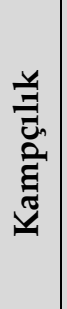 & 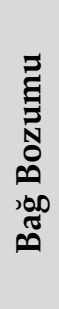 & 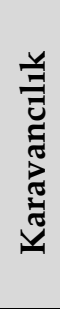 & 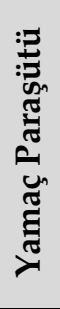 & 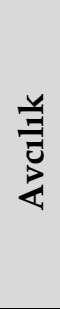 & 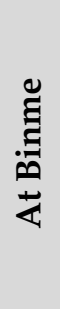 & 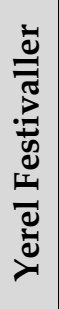 & 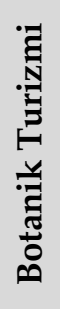 & 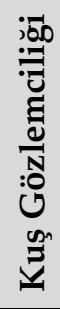 & 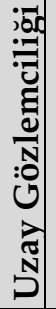 & 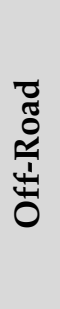 & 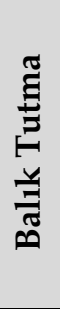 & 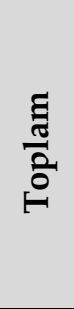 \\
\hline $\mathrm{K} 1$ & $E$ & & $*$ & & $*$ & & $*$ & $*$ & $*$ & & & & & & & 5 \\
\hline $\mathrm{K} 2$ & $E$ & $*$ & $*$ & $*$ & $*$ & & & $*$ & & & & & & & & 5 \\
\hline $\mathrm{K} 3$ & $E$ & $*$ & $*$ & $*$ & & & & & & $*$ & $*$ & & & & & 5 \\
\hline $\mathrm{K} 4$ & $E$ & & $*$ & $*$ & $*$ & & & & & & $*$ & & & $*$ & & 5 \\
\hline K5 & $\mathrm{K}$ & & & $*$ & & & $*$ & $*$ & & $*$ & & $*$ & & & & 5 \\
\hline K6 & $E$ & $*$ & & $*$ & & $*$ & & $*$ & $*$ & & & & & & & 5 \\
\hline K7 & $E$ & & * & $*$ & & $*$ & & $*$ & $*$ & & & & & & & 5 \\
\hline K8 & K & $*$ & $*$ & $*$ & * & $*$ & & & & & & & & & & 5 \\
\hline K9 & $E$ & $*$ & & & $*$ & $*$ & $*$ & $*$ & & & & & & & & 5 \\
\hline K10 & $E$ & $*$ & $*$ & & $*$ & $*$ & $*$ & & & & & & & & & 5 \\
\hline K11 & $\mathrm{K}$ & $*$ & & $*$ & & $*$ & $*$ & & & $*$ & & & & & & 5 \\
\hline K12 & $\mathrm{K}$ & $*$ & $*$ & $*$ & $*$ & $*$ & & & & & & & & & & 5 \\
\hline $\mathrm{K} 13$ & $E$ & $*$ & $*$ & $*$ & $*$ & & & & $*$ & & & & & & & 5 \\
\hline $\mathrm{K} 14$ & $E$ & $*$ & & $*$ & & & $*$ & & & $*$ & & & $*$ & & & 5 \\
\hline K15 & $\mathrm{K}$ & $*$ & $*$ & $*$ & & & & & $*$ & & $*$ & & & & & 5 \\
\hline K16 & $\mathrm{K}$ & $*$ & $*$ & & & & $*$ & & $*$ & & & $*$ & & & & 5 \\
\hline K17 & E & $*$ & $*$ & $*$ & * & $*$ & & & & & & & & & & 5 \\
\hline $\mathrm{K} 18$ & $E$ & $*$ & $*$ & & * & $*$ & * & & & & & & & & & 5 \\
\hline K19 & $\mathrm{K}$ & $*$ & $*$ & $*$ & $*$ & $*$ & & & & & & & & & & 5 \\
\hline K20 & $E$ & $*$ & $*$ & & & $*$ & $*$ & $*$ & & & & & & & & 5 \\
\hline $\mathrm{K} 21$ & $E$ & $*$ & $*$ & $*$ & $*$ & & $*$ & & & & & & & & & 5 \\
\hline \multicolumn{2}{|c|}{ Toplam } & 17 & 16 & 15 & 12 & 11 & 10 & 7 & 6 & 4 & 3 & 2 & 1 & 1 & 0 & 105 \\
\hline \multicolumn{2}{|c|}{$\begin{array}{c}\text { Frekans } \\
\text { yüzdesi \% }\end{array}$} & حِ & $\stackrel{N}{n}$ & $\stackrel{M}{+}$ & $\stackrel{+}{\rightleftarrows}$ & ?2 & aे & $\widehat{\sigma}$ & ثิ & $\stackrel{\infty}{\oplus^{\circ}}$ & $\hat{\imath}$ & $\stackrel{\rho}{-}$ & o. & $\hat{\sigma}$ & 0 & $\underset{1}{8}$ \\
\hline \multicolumn{2}{|c|}{$\begin{array}{c}\text { Katılımcı } \\
\text { yüzdesi \% }\end{array}$} & $\hat{\infty}$ & $\tilde{n}$ & $\stackrel{+}{N}$ & 공 & में & $\begin{array}{l}0 \\
\stackrel{2}{F}\end{array}$ & $\hat{m}^{m}$ & $\begin{array}{l}0 \\
\infty^{\circ} \\
\text { i }\end{array}$ & $\stackrel{2}{\sim}$ & $\stackrel{m}{\underset{-}{*}}$ & on & $\stackrel{\infty}{+}$ & $\stackrel{\infty}{\rightarrow}$ & 0 & \\
\hline
\end{tabular}

Not: Matriste katılımcı sırası karışık olarak verilmiştir. 
Tablo 3'te odak grup görüşmelerine katılanların, COVID-19 salgını sürecinde Zile'de gerçekleştirilebilecek uygun kırsal turizm aktivitelerine yönelik görüşlerinin detaylı olarak sunulduğu bir matris görülmektedir. Bu matrisin oluşturulma amacı, araştırmadan elde edilen verilerin daha anlaşılır ve görünür hale gelmesini sağlamaktır. Katılımcılara pandemi sürecinde turizmin durumu anlatılarak kırsal turizme dair bilgilendirmeler yapıldıktan sonra, her katılımcıdan Zile'ye uygun 5'er adet aktivite belirtmesi istenmiştir. Bunun neticesinde odak grup katılımcılarından elde edilen toplamda 105 adet görüş ortaya çıkmıştır. Bu görüşlerin en değerli yanı, yarı-yapılandırılmış görüşme tekniği ile konuya hâkim bireylerden elde edilmesinden dolayı güvenilir, doğru ve objektif bilgileri içermesidir. Matrise bakıldığında Grafik 1'de öne çıkan türlerin katılımcı görüşlerine nasıl yansıdığı görülebilmekte ve öne çıkan türlerin tüm görüşlere ve katılımcılara oranları ayrı ayrı incelenebilmektedir. Dolayısıyla elde edilen veriler, konuyla ilgilenen bireyler tarafından karşılaştırmalı olarak kontrol edilebilmekte ve çözümlenebilmektedir.

Anadolu'nun en eski yerleşim yerlerinden biri olan Tokat'ın Zile ilçesi, tarihi ve doğal varlıklarıyla önemli bir turizm potansiyeli barındırmaktadır. Kırsal turizm anlamında da önemli bir potansiyele sahip olan Zile'ye yönelik gerçekleştirilen bu çalışmada, dikkate değer veriler elde edilmiştir. Bu verileri daha iyi yorumlamak ve tartışabilmek açısından bir SWOT (GZTF) analizi yapılmıştır. SWOT analizi bir stratejinin formüle edilmesini sağlayabilmek için yapılandırılmış bir metot olarak bilinmektedir. SWOT analizinin amac, bir durumu değerlendirmek için onun "Güçlü ve Zayıf" yönlerini belirleyerek, aynı durum çerçevesinde gelişen "Fırsat ve Tehdit" unsurlarını tanımlamaktır. Söz konusu duruma yönelik SWOT unsurlarının tanımlanması neticesinde, ilgili durumun güçlü yönlerini ön plana çıkaran, zayıf yönlerini minimize eden, çevredeki fırsatlardan yararlanan ve tehditlere karşı koyan en doğru stratejilerin geliştirilmesi mümkündür (Dyson, 2004: 632). Aşağıda bulunan Tablo 4'te Zile'de COVID-19 sonrası kırsal turizm aktivitelerine yönelik SWOT matrisi yer almaktadır.

Tablo 4'te görülen SWOT matrisine göre Zile' de kırsal turizm anlamında önemli bir potansiyelin varlığı söz konusudur. Özellikle bağcılık gibi geleneksel tarımsal faaliyetlerin uzun yıllardır sürdürülmesi ve zirai açıdan çok çeşitli ürün yetiştiriciliğinin yapılması tarım turizmi anlamında yörenin güçlü olduğu yönlerden biridir. Yörenin kırsal turizm aktiviteleri açısından diğer güçlü yönleri arasında doğa yürüyüşü, kamping-karavancıllk gibi türlere elverişli ortam sağlaması gösterilebilir. Aynı zamanda Zile'nin nüfus yoğunluğunun az olmasının da COVID-19 sonrası sosyal mesafeli turizm anlayışına uyumlu bir yapı sergilediği söylenilebilir. Ayrıca Tablo 4'e göre ulaşım altyapısına yapılmakta olan yatırımlar ve sosyal platformlardaki tanıtım imkânlarının artması gibi durumlar Zile'de kırsal turizm için önemli fırsatlar sunmaktadır.

Tablo 4'ten hareketle yukarda bahsi geçen olumlu durumlar Zile'nin kırsal turizm anlamında potansiyelini ortaya koymaktadır. Ancak bu potansiyeli harekete geçirecek noktalarda bazı eksiklikler ve risklerin olduğu da göze çarpmaktadır. Buna göre tanıtım eksikliği, kamp ve karavancılık gibi türlerin altyapısal sorunları, başlıca doğa yürüyüş rotalarının düzenlenmemiş olması Zile'nin kırsal turizmdeki en önemli zayıflıkları arasında gösterilebilir. Öte yandan COVID-19 salgınındaki vaka sayısının yeniden artması ve seyahat engellerinin başlaması gibi olasılıklar ile rakip destinasyonların daha erken davranıp kendi kırsal turizm potansiyelini harekete geçirmesi Zile için tehdit unsurları olmaktadır. 
Tablo 4: COVID-19 sonrası Zile'de kırsal turizm aktivitelerine yönelik SWOT matrisi

\begin{tabular}{|c|c|}
\hline GÜÇLÜ YÖNLER & ZAYIF YÖNLER \\
\hline $\begin{array}{l}\text { - Zile'nin genel olarak kırsal turizme uygun } \\
\text { alanlarının fazla olması } \\
\text { - Zile'de bağcllı ve tarımsal faaliyetlerin çok } \\
\text { eski zamanlardan beri yapılması } \\
\text { - Nüfus kalabalığının az olması ve COVID-19 } \\
\text { sonrası sosyal mesafeye uygun ortamlar } \\
\text { barındırması } \\
\text { - Trekking aktivitelerine yönelik önemli } \\
\text { derecede potansiyelinin olması } \\
\text { - Kamp ve Karavan turizmi uygulanabilecek } \\
\text { alanlara sahip olması } \\
\text { - Yerel karar vericilerin kırsal turizm } \\
\text { aktivitelerini destekleme konusunda istekli } \\
\text { olması }\end{array}$ & $\begin{array}{l}\text { - Zile'de turizme yönelik yeterli düzeyde } \\
\text { tanıtım faaliyetinin yapılmamış olması } \\
\text { - Karavan parkı ve kamp tesisi bulunmaması } \\
\text { - Trekking faaliyetlerine yönelik yürüyüş } \\
\text { rotalarının belirlenmemiş olması } \\
\text { - Zile'nin ulaşım imkânlarının yeterli } \\
\text { düzeyde gelişmemiş olması } \\
\text { - Butik tarzda konaklama imkânı (tarihi } \\
\text { konak, köy evi vb.) potansiyelinin fazla } \\
\text { olmasına rağmen, konaklama işletmesi } \\
\text { sayısının yeterli düzeyde olmaması }\end{array}$ \\
\hline FIRSATLAR & TEHDITLER \\
\hline $\begin{array}{l}\text { - COVID-19 neticesinde kırsalda yapılacak } \\
\text { kamp-karavan gibi turizm türlerine yönelik } \\
\text { talebin artması } \\
\text { - Zile'nin sakin şehir potansiyelinin bulunması } \\
\text { - Son yıllarda gittikçe popüler hale gelen sosyal } \\
\text { medya (Facebook, Instagram, Twitter vb.) } \\
\text { platformlarında, Zile'ye yönelik tanitım } \\
\text { olanağının bulunması } \\
\text { - Başta Ankara olmak üzere birçok şehri } \\
\text { Tokat'a bağlayacak olan ve Zile'den geçen } \\
\text { duble yol çalışmasının devam etmesi }\end{array}$ & $\begin{array}{l}\text { - COVID-19 salgının tekrar kontrolden } \\
\text { çıkma ihtimali ve neticesinde olabilecek } \\
\text { seyahat engeli } \\
\text { - Yakın bölgelerdeki rakip destinasyonların } \\
\text { varlığı } \\
\text { - Kırsal turizm faaliyetlerinin amacından } \\
\text { saparak doğayı tahrip edebilme ihtimali }\end{array}$ \\
\hline
\end{tabular}

\section{SONUÇ ve ÖNERILER}

COVID-19 pandemisi sebebiyle uluslararası seyahat kısıtlamaları hayata geçirilmiş ve insanların turizme yönelik taleplerinde ciddi düşüşler meydana gelmiştir. Ayrıca insanların turizm tercihlerinde değişiklikler yaşanmış (Higgins-Desbiolles, 2020), bireysel faaliyetlerin yapılabildiği ve sosyal mesafenin korunabildiği kırsal turizm aktivitelerine yönelme başlamıştır.

Çalışma kapsamında yapılan odak grup görüşmelerinde, Zile'de trekking yani doğa yürüyüşü kırsal turizm anlamında en fazla ön plana çıkan aktivite olmuştur. Zile'nin bu anlamda çok büyük bir potansiyelinin olduğu söylenilebilir. Trekkinge ve bisiklete uygun rotaların bir envanter çalışmasıyla belirlenip, işaretleme sistemleri ve rehber olanakları sağlanmalıdır. Trekking ve bisiklet, COVID-19 sonrası artan bireysel veya sosyal mesafeye uygun faaliyetler arasında olduğu için ve kırsal alanlarda gerçekleştirildiğinden, özellikle yerli turizm anlamında faydalı bir aktivite niteliğindedir (Vos, 2020).

Turistik değerleri harekete geçirmede ve destinasyonda iyi bir imaj oluşturmada etkin ve doğru bir tanıtım stratejisi olmazsa olmazdır (Baloğlu ve McCleary, 1999). Ancak Zile'nin turizm anlamında tanıtım açısından eksikliği bulunmaktadır. Dolayısıyla Zile'nin yerel karar vericileri tanıtım anlamında doğru stratejilerle, güçlü adımlar atmalıdır. Özellikle sosyal medyanın Zile'de turizm tanıtımı konusunda aktif kullanımı, çağa uygun bir yöntem olarak tercih edilmelidir. Öte 
yandan Zile'deki en büyük eksikliklerden biri de COVID-19 pandemisi ile birlikte popüler olan kamp-karavan gibi türlerde çok fazla potansiyelinin olmasına rağmen, altyapı yatırımlarının bulunmamasıdır. Karavan turizmi katılımcıları ve kampçılar bu konuda altyapısı olan alanlara yönelmektedirler. Özellikle karavan parkı ve kamp alanı gibi yatırımların hayata geçirilmesi, gittikçe büyüyen bu pastadan pay almak için mutlaka planlanmalıdır.

Zile'nin yıllardan beri çözüm bekleyen sorunlarından biri olan ulaşım sorunu zayıf yönlerinden biridir. Ancak yapımı devam eden Ankara-Tokat duble yolu Zile' den geçmektedir ve bu anlamda önemli bir fırsat yaratmaktadır. Ulaşım altyapısının güçlü olması bir destinasyona turist gelebilmesi için en hayati konulardan biridir (Coleman, 1997; İçöz, 1998; Hall ve Page, 2002). Dolayısıyla, Zile'ye turist erişimini kolaylaştıracak olan bu yolun mutlaka bitirilmesi gerekmektedir. Yerel ve ulusal karar vericilere bu konuda büyük görevler düşmektedir.

Sonuç olarak bu araştırma Zile ilçesiyle sınırlı bir nitelik arz ettiğinden, COVID-19 sonrası değişen turist tercihleri neticesinde kırsal turizm gibi sosyal mesafeye uygun aktiviteler içeren türlerin farklı destinasyonlara da yönelik incelemesi yapılabilir. Bununla birlikte, araştırmanın bir diğer sınırlılığ1 pandemi nedeniyle çok fazla kişiyle temas etmemek amacıyla odak grup görüşmesi şeklinde yapılmasıdır. Ancak ileriki dönemlerde bu konuda çalışmayı düşünen araştırmacılar için eğer imkân bulunursa anket vb. yöntemlerle de çalışmalar yapılması önerilebilir. Öte yandan bu çalışmanın bulgularından ve bulgular neticesinde geliştirilen önerilerden yerel karar vericiler başta olmak üzere tüm paydaşlar yararlanabilir.

\section{KAYNAKÇA}

Abu Bakar, N.A. and Rosbi, S. (2020). Effect of Coronavirus Disease (COVID-19) to Tourism Industry, International Journal of Advanced Engineering Research and Science, 7(4): 189-193. DOI: 10.22161/ijaers.74.23.

Acar, Y. (2020). Yeni Koronavirüs (Covid-19) Salgını ve Turizm Faaliyetlerine Etkisi, Güncel Turizm Araştırmaları Dergisi, 4(1): 7-21. DOI: 10.32572/guntad.703410.

Anadolu Ajansı. (2020). Korona Günlerine 'Karavan Tatili' Damgasını Vuruyor. [Online] https://www.aa.com.tr/tr/turkiye/korona-gunlerine-karavan-tatili-damgasini-vuruyor/1863216 [Erişim Tarihi: 17.06.2020].

Artuğer, S. and Kendir, H. (2013). Agritourist Motivations: The Case of Turkey, International Journal of Business and Management. 8(21): 63-70. DOI: 10.5539/ijbm.v8n21p63

Artuğer, S., Özkoç, A. G. ve Kendir, H. (2013). Ta-Tu-Ta (Tarım-Turizm-Takas) Çiftliklerinin Pazarlanması ve Tanıtılması için Öneriler, Uluslararası Sosyal ve Ekonomik Bilimler Dergisi, 3: 1-5.

Aydın, O. (2012). AB'de Kırsal Turizmde İlk 5 Ülke ve Türkiye'de Kırsal Turizm, KMÜ Sosyal ve Ekonomik Araştırmalar Dergisi, 14(23): 39-46.

Bahar, O. ve Çelik İlal, N. (2020). Coronavirüsün (Covid-19) Turizm Sektörü Üzerindeki Ekonomik Etkileri, International Journal of Social Sciences and Education Research, 6(1). 125-139.

Baker, D.M. (2015). Tourism and The Health Effects of Infectious Diseases: Are There Potential Risks for Tourists?, International Journal of Safety and Security in Tourism and Hospitality, 12(3): 117. [Online] https://www.palermo.edu/Archivos_content/2015/economicas/journaltourism/edicion12/03_Tourism_and_Infectous_Disease.pdf [Erişim Tarihi: 01.06.2020].

Baloğlu, S. and McCleary, K.W. (1999). A Model of Destination Image Formation, Annals of Tourism Research, 26(4): 868-897. 
Bramwell, B. (1994). Rural Tourism and Sustainable Rural Tourism, Journal of Sustainable Tourism, 2(1-2): 1-6.

Campon-Cerro, A. M., Hernandez-Mogollon, J. M. and Alves, H. (2017). Sustainable Improvement of Competitiveness in Rural Tourism Destinations: The Quest for Tourist Loyalty in Spain, Journal of Destination Marketing \& Management, 6(3): 252-266.

Canoves, G., Villarino, M., Priestley, G.K. and Blanco, A. (2004). Rural Tourism in Spain: An Analysis of Recent Evolution, Geoforum, 35: 755-769.

Chang, C.L., McAleer, M. and Ramos, V. (2020). A Charter for Sustainable Tourism after COVID19, Sustainability 12: 1-4. DOI: 10.3390/su12093671

Coğrafya Harita. (2020). Tokat İlinin Konumu ve Siyasi Haritası. [Online] http://cografyaharita.com/turkiye_mulki_idare_haritalari5.html [Erişim Tarihi: 06.07.2020].

Coleman, C. (1997). Tourist Traffic in English National Parks-An Innovative Approach to Management, The Journal of Tourism Studies, 8(1): 2-15.

Cucari, N., Wankowicz, E. and De Falco, S.E. (2019). Rural Tourism and Albergo Diffuso: A Case Study for Sustainable Land-Use Planning, Land Use Policy, 82: 105-119.

Çeken, H., Dalgın, T. ve Çakır, N. (2012). Bir Alternatif Turizm Türü Olarak Kırsal Turizmin Gelişimini Etkileyen Faktörler ve Kırsal Turizmin Etkileri, Uluslararası Sosyal ve Ekonomik Bilimler Dergisi, 2(2): 11-16.

Çeken, H., Karadağ, L. ve Dalgın, T. (2007). Kırsal Kalkınmada Yeni Bir Yaklaşım Kırsal Turizm ve Türkiye'ye Yönelik Teorik Bir Çalışma, Artvin Çoruh Üniversitesi Orman Fakültesi Dergisi, 8(1): $1-14$.

Deveci, B., Türkmen, S. ve Avcıkurt, C. (2013). Kırsal Turizm ile Gastronomi Turizmi İlişkisi: Bigadiç Örneği, Uluslararası Sosyal ve Ekonomik Bilimler Dergisi, 3(2): 29-34.

Dönmez, Y., Kendir, H., Türkmen, F. ve Çabuk, S. (2017). Tarihi Evlerin Kültür Turizmine Etkilerinin Araştırılması: Tokat-Zile Örneği, Uluslararası Taşköprü Pompeipolis Bilim Kültür Sanat Araştırmaları Sempozyumu, Kastamonu Üniversitesi 10-12 Nisan 2017. Kastamonu. ss: 1114-1127.

Dyson, R.G. (2004). Strategic Development and SWOT Analysis at The University of Warwick, European Journal of Operational Research, 152(3): 631-640.

Fleischer, A. and Pizam, A. (1997). Rural tourism in Israel, Tourism Management, 18(6): 367-372.

Gössling, S., Scott, D. and Hall, C.M. (2020). Pandemics, Tourism and Global Change: A Rapid Assessment of COVID-19, Journal of Sustainable Tourism, 1-20. DOI: 10.1080/09669582.2020.1758708.

Hall, C. and Page, S. (2002). Geography of Recreation and Tourism. London: Psychology Press.

Higgins-Desbiolles, F. (2020). Socialising Tourism for Social and Ecological Justice after COVID19, Tourism Geographies, 1-14. DOI: 10.1080/14616688.2020.1757748.

Hollingsworth, T.D., Ferguson, N.M. and Anderson, R.M. (2007). Frequent Travelers and Rate of Spread of Epidemics, Emerging Infectious Diseases, 13(9): 1288-1294. DOI: 10.3201/eid1309.070081.

Hoque, A., Shikha, F.A., Hasanat, M.W., Arif, I. and Hamid, A.B.A. (2020). The Effect of Coronavirus (COVID-19) in The Tourism Industry in China, Asian Journal of Multidisciplinary Studies, 3(1): 52-58. 
İçöz, O. (1998). Seyahat Acentaları ve Tur Operatörlü̈̆̈̈ Yönetimi. Ankara: Turhan Kitabevi.

Karabatı, S., Doğan, E., Pınar, M. and Çelik, L.M. (2009). Socio-Economic Effects of Agri-Tourism on Local Communities in Turkey: The Case of Aglasun, International Journal of Hospitality $\mathcal{E}$ Tourism Administration, 10: 129-142. DOI: 10.1080/15256480902851032.

Kastenholz, E., Carneiro, M.J., Marques, C.P. and Lima, J. (2012). Understanding and Managing the Rural Tourism Experience - The Case of a Historical Village in Portugal, Tourism Management Perspectives, 4: 207-214.

Kastenholz, E., Carneiro, M.J., Marques, C.P. and Loureiro, S.M.C. (2018). The Dimensions of Rural Tourism Experience: Impacts on Arousal, Memory, and Satisfaction, Journal of Travel $\mathcal{E}$ Tourism Marketing, 35(2): 189-201.

Kastenholz, E., Davis, D. and Paul, G. (1999). Segmenting Tourism in Rural Areas: The Case of North and Central Portugal, Journal of Travel Research, 37: 353-363.

Khartishvili, L., Muhar, A., Dax, T. and Khelashvili, I. (2019). Rural Tourism in Georgia in Transition: Challenges for Regional Sustainability, Sustainability, 11(410): 2-20.

Lane, B. (1994). What is Rural Tourism?, Journal of Sustainable Tourism, 2(1-2): 7-21.

Lee, C.C. and Chen, C.J. (2011). The Reaction of Elderly Asian Tourists to Avian Influenza and SARS, Tourism Management, 32(6): 1421-1422. DOI: 10.1016/j.tourman.2010.12.009.

Li, Q., Guan, X., Wu, P., Wang, X., Zhou, L. and Tong, Y. (2020). Early Transmission Dynamics in Wuhan, China, of Novel Coronavirus-Infected Pneumonia, New England Journal of Medicine, 382(13): 1199-1207. DOI: 10.1056/NEJMoa2001316.

Lu, H., Stratton, C. W. and Tang, Y. W. (2020). Outbreak of Pneumonia of Unknown Etiology in Wuhan, China: The Mystery and The Miracle, Journal of Medical Virology, 92: 401-402. DOI: 10.1002/jmv.25678.

McAleer, M., Huang, B., Kuo, H., Chen, C. and Chang, C. (2010). An Econometric Analysis of SARS and Avian Flu on International Tourist Arrivals to Asia, Environmental Modelling \& Software, 25(1): 100-106. DOI: 10.1016/j.envsoft.2009.07.015.

Özdemir Yılmaz, G. ve Kafa Gürol, N. (2012). Balıkesir İlinin Kırsal Turizm Potansiyelinin Değerlendirilmesi, KMÜ Sosyal ve Ekonomik Araştırmalar Dergisi, 14(23): 23-32.

Page, S.J. and Getz, D. (1997). The Business of Rural Tourism: International Perspectives. UK: International Thomson Business Press.

Pine, R. and McKercher, B. (2004). The Impact of SARS on Hong Kong's Tourism Industry, International Journal of Contemporary Hospitality Management, 16(2): 139-143.

Richardson, S., March, R., Lewis, J. and Radel, K. (2012). Analysing The Impact of the 2011 Natural Disasters on the Central Queensland Tourism Industry, TEAM Journal of Hospitality and Tourism, 9(1): 1-14.

Roberts, L. and Hall, D. (2001). Rural Tourism and Recreation: Principles to Practice. UK: Cabi Publishing.

Soykan, F. (2003). Kırsal Turizm ve Türkiye Turizmi için Önemi, Ege Coğrafya Dergisi, 12: 1-11.

Trak, İ. ve Zengin, M. (1994). Zile. Ankara: Kale Ofset Matbaacıllk.

TÜİK (Türkiye İstatistik Kurumu). (2020). Tokat İli Zile İlçesi 2019 Yılı Toplam Nüfus Sayısı. [Online] https://biruni.tuik.gov.tr/medas/?locale=tr [Erişim Tarihi: 07.07.2020]. 
UNWTO. (2011). International Tourists to Hit 1.8 Billion by 2030 . [Online] https://www.unwto.org/archive/global/press-release/2011-10-11/international-tourists-hit-18billion-2030 [Erişim Tarihi: 31.05.2020].

UNWTO. (2019). International Tourism Highligts. [Online] https://www.eunwto.org/doi/pdf/10.18111/9789284421152 [Erişim Tarihi: 31.05.2020].

UNWTO. (2020). International Tourist Numbers could Fall 60-80\% in 2020, UNWTO Reports. [Online] https://www.unwto.org/news/covid-19-international-tourist-numbers-could-fall-60-80in-2020 [Erişim Tarihi: 31.05.2020].

Ural, A. ve Kılıç, İ. (2013). Bilimsel Araştırma Süreci ve SPSS ile Veri Analizi. Ankara: Detay Yayıncilik.

Ünlüönen, K. ve Çeti, B. (2019). Salgın Hastalıklar Sebebiyle Oluşan Krizlerin Turizm Sektörü Üzerindeki Etkisinin Değerlendirilmesi, AHBVÜ Turizm Fakültesi Dergisi, 22(2): 109-128. DOI: 10.34189/tfd.22.2.001.

Voase, R. (1995). Tourism: The Human Perspective. London: Hodder and Stoughton.

Vos, D.J. (2020). The Effect of COVID-19 and Subsequent Social Distancing on Travel Behavior, Transportation Research Interdisciplinary Perspectives, 5: 1-3. DOI: 10.1016/j.trip.2020.100121.

Wang, D., Hu, B., Hu, C., Zhu, F., Liu, X., Zhang, J. and et al. (2020). Clinical Characteristics of 138 Hospitalized Patients with 2019 Novel Coronavirus-Infected Pneumonia in Wuhan, China, Jama, 323(11): 1061-1069. DOI: 10.1001/jama.2020.1585.

WHO (2020). Rolling Updates on Coronavirus Disease (COVID-19). [Online] https://www.who.int/emergencies/diseases/novel-coronavirus-2019/events-as-they-happen [Erişim Tarihi: 30.05 .2020$]$.

Worldometer (2020). Covid-19 Coronavirus Pandemic: Reported Cases and Deaths by Country, Territory, or Conveyance. [Online] https://www.worldometers.info/coronavirus/ [Erişim Tarihi: 20.07.2020].

Yıldırım, A. ve Şimşek, H. (2005). Sosyal Bilimlerde Nitel Araştırma Yöntemleri. Ankara: Seçkin Yayıncilik.

Zile Belediyesi. (2020). Zile'nin Tarihi ve Coğrafyası. [Online] http://web.zile.bel.tr/sayfa/tarihive-cografyasi.html [Erişim tarihi: 07.07.2020]. 